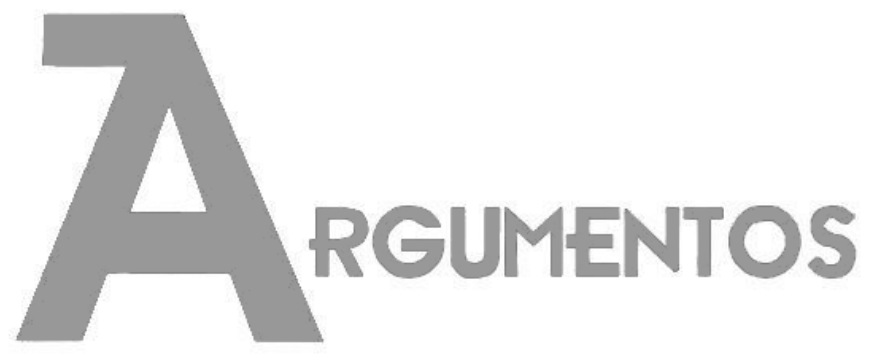

Vol. 16, n. 2, jul./dez. 2019 ISSN: 2527-2551 (online)

http://www.periodicos.unimontes.br/argumentos

\title{
Entrevista com Vera Cepêda
}

Entrevistadores:

José Henrique Artigas de Godoy ${ }^{1}$

Moacir de Freitas Junior ${ }^{2}$

Recebido em: 30/07/2019

Aprovado em: 26/08/2019

Vera Alves Cepêda possui graduação em Ciências Sociais pela Universidade de São Paulo (1992), mestrado e doutorado em ciência política pela Universidade de São Paulo (1998; 2004) e pósdoutorado em ciência política pelo IESP/UERJ (2016). Atualmente é professora do Departamento de Ciências Sociais da Universidade Federal de São Carlos/UFSCar na graduação, atuando no Programa de Pós-graduação em Ciência Política (PPGPol) e no Programa de Pós-Graduação em Sociologia (PPGS). Desenvolve pesquisas no campo do pensamento político e social brasileiro, em especial nos temas das interpretações sobre o Brasil, na atuação de instituições, intel ectuais e teorias ligados ao problema do desenvolvimento, da democracia e das capacidades e ação do Estado em contexto periférico. Pesquisa também o processo de construção e os resultados de políticas públicas para inclusão social e equidade em período recente.

Vera, primeiro, gostaríamos de agradecer pela oportunidade de lhe entrevistar para o nosso dossiê. Muito obrigado! Você é uma referência para nós do campo do Pensamento Brasileiro e gostaríamos de começar perguntand o a você um pouco de sua trajetória. Como foi que você escolheu o Pensamento Brasileiro como área de pesquisa e que caminhos trilhou para chegar até aqui?

\footnotetext{
1 Doutor em Ciência Política pela Universidade de São Paulo, Brasil, é professor associado do Departamento de Ciências Socia is (DCS) e do Programa de Pós-Graduação em Ciência Política e Relações internacionais (PPGCPRI) do Centro de Ciências Humanas Letras e Artes da Universidade Federal da Paraíba (CCHLA-UFPB), Brasil.E-mail: jhartigasgodoy@gmail.com. ORCID: https://orcid.org/0000-00029580-1841

2 Doutor em Ciências Sociais pela Unesp de Araraquara, Brasil, é professor adjunto do Instituto de Ciências Sociais - INCIS e do Programa de Pós-Graduação em Ciências Socia is do INCIS, da Universida de Federal de Uberlândia, Brasil. E-mail: mfjr@ufu.br. ORCID: https://orcid.org/0000-0001-7174-7177.
} 
Desde meu ingresso na universidade o tema das representações políticas me perseguiu. Me parecia, e ainda parece, natural que no campo das ciências humanas, que parte do pressuposto que toda realidade vivida é baseada em um ponto no "estar no mundo e na história" (o pressuposto ontológico do "socialmente determinado") o peso das construções ideológicas seja fundamental. No entanto, me admira o equívoco comum de atribuir às representações um caráter basicamente estático e ex post. Dou como exemplo a recorrente percepção dos indivíduos como sendo dotados de interesses e de valores per si., como elementos anteriores à cadeia da representação sendo esta, por consequência, a expressão desses interesses e perspectivas. Eu não entendo as construções ideacionais, o pensamento ou as ideologias dessa forma. Ao contrário, creio que é no processo de sua fabricação que a identidade social e individual vai sendo definida, gerando os limites identitários que reagem, opõem-se, dialogam e se ressignificam no encontro/competição de formulações distintas. Nesse sentido creio mais na construção dos construtos ideacionais como parte e elemento da dinâmica da produção do social, menos do que a re(a)presentação de algo já constituído. E uma vez fixada as fronteiras de um corpo de ideias (escolas, paradigmas, famílias, linhagens ou ideologias) elas são parte ativa da definição de interesses ou de valores.

Há, portanto, uma interação dinâmica no campo das ideias, que permitem dois movimentos analíticos importantes: o primeiro, é que a partir do exame da produção ideológica (e aqui penso ideologia na brilhante chave da sociologia do conhecimento proposta por Mannheim) é possível compreender parte do cenário, das tensões e dos problemas com os quais a elaboração ideacional está conectada. Desta forma, a análise do campo do pensamento social estabelece uma ferramenta metodológica para produção de conhecimento sociológico, político e intelectual em um momento histórico específico (eixo sincrônico) ou na sua transformação (eixo diacrônico). Como diria Mannheim, não se trata de olhar as ideologias, o pensamento social, como quadros em um museu, mas sim compreender que elementos estão na configuração mental, material e nas escolhas que resulta em um determinado desenho social. O segundo movimento é entender a produção, circulação, recepção ou ressignificação das ideias como expressão de um campo político, uma arena que impacta na orientação concreta da ação dos indivíduos e da sociedade. Uma "visão de mundo" é elemento vital da 
fundamentação do "estar no mundo" e deixa legados que podem ter longa duração na vida das sociedades (como a perspectiva das "linhagens" políticas da trajetória brasileira).

Procurar o lugar e as funções das ideias a partir do estudo de seus processos de produção faz parte da minha identidade de pesquisadora e talvez tenha resultado da combinação simultânea do interesse pela comunicação social, pela filosofia e pela ciências sociais (escolha final de campo de saber e atuação). Na graduação, tive a sorte de ter vários professores sensíveis ao tema e mais ainda por ter encontrado o Gildo Marçal Brandão e seu grupo de pesquisa. Nesse momento associei essa perspectiva de trabalho ao problema do pensamento social e político brasileiro, escolhendo o binômio economia \& política como chave de meus trabalhos: no caso brasileiro, de uma sociedade que pensou, formulou e experimentou na prática um projeto orientado de mudança social desde a revolução de 1930, a racionalidade econômica praticamente modelou boa parte das escolhas políticas. Se em um primeiro momento o tema da identidade, o problema da formação e os dilemas conscientes do "atraso" produziram uma agenda intelectual forte, mobilizando a reflexão de inúmeros autores desde o final do século XIX, a metamorfose de "atraso" em subdesenvolvimento juntou economia e projeto político, sendo parte fundante das nossas formas políticas e do processo de modernização. E, mais ainda, no caso brasileiro, as ideias organizadas (as ideologias) tiveram forte protagonismo nessa trajetória.

Em resumo, nessa perspectiva passei pelo mestrado estudando a obra de Celso Furtado, no doutorado analisando o processo de formação da ideologia industrialista em Roberto Simonsen e voltei na pesquisa de pós-doutorado à Furtado, procurando as persistências e mudanças na percepção da democracia na obra desse autor.

Após um longo período estudando o pensamento "progressista" do nacionaldesenvolvimentismo fiz um salto recente em direção oposta, observando tanto a formação de um pensamento de direita no Brasil (o corporativismo nos anos 30) quanto suas ressignificações recentes.

\section{Como você vê nosso campo de pesquisas hoje?}


Em expansão e por mais de um motivo. Exatamente porque não dá para entender a história social e política brasileira sem recorrer ao estudo do pensamento social (em especial entre o final do século XIX e a década de 1970), os trabalhos da área tendem a manter um papel importante e constante. Ainda neste ângulo, exatamente porque até um trabalho pretensamente objetivo foi produzido segundo as condições e demandas de uma época (um contexto) ele pode e deve ser revisto, tornando alvo, por sua fez, de uma análise de seu processo de construção (revelador de importantes elementos do cenário em que emerge). No campo da teoria social e política, essa situação é ainda mais dinâmica, uma vez que as teses produzem um movimento de contínua (e necessária) revisitação. Pensamento social e político fala simultaneamente muitas línguas - a do objeto estudado, a dos recortes e explicações possíveis no caleidoscópio dos fenômenos sociais, a do pesquisador e suas escolhas, a da circulação e recepção de ideias, etc. - e revela muita configuração social.

Um segundo ângulo é o da conjuntura atual. Durante as últimas décadas entendemos as instituições democráticas como estáveis no Brasil. A partir da década de 1990, em especial, a luta política foi centralizada na disputa político-eleitoral, no processo de governança e na definição de agenda macroeconômica e de políticas públicas. No quadro recente essa estabilidade ruiu, independentemente de quais fatores expliquem sua crise, e colocou em marcha uma grave e duríssima disputa ideológica, como há muito não se via no país (e também não dessa forma e meios). $A$ crise, que atravessa partidos e instituições, revela a face da disputa entre visões de mundo e projetos políticos (da grande política) e tem poder de arrastá-los para outra formatação (como já ocorreu em 1930, 1937 e 1964).

Em um momento de crise as maneiras de organizar as opções de mudança porque as formas do ontem recente não contemplam mais os desafios do hoje e do amanhã - potencializam as formas e o encadeamento do pensar, reforçando o peso da ideologia e do pensamento. Para entender sociedade e política no Brasil atual é importante saber de onde e por quais motivos essa dimensão ideológica surgiu (ou ressurgiu) e quais são as alternativas de futuro nelas envolvidas. Portanto, a área de pensamento social, de pensamento político e da teoria política têm muito a contribuir, pelo estoque de conhecimento acumulado sobre essa dimensão ideacional e pelo 
repertório téorico-conceitual, que somadas à outras subáreas podem ajudar a lançarluz sobre o imbróglio atual.

Seu último texto sobre as novas direitas no Brasil desnudou uma importante questão, que é o fato de que elas buscam criar um novo campo político e intelectual, dotado de ideias próprias, baseadas em um princípio de que a desigualdade é algo "natural" e, portanto, incapaz de ser superada pela ação humana e pelas políticas públicas, pelo Estado ou pela sociedade. Você poderia nos falar mais sobre estas ideias? As "novas direitas" tem ligação com o pensamento conservador brasileiro ou procuram dele se distanciar?

Se há algo que aprendi no estudo do pensamento social e político brasileiro é que não é fácil produzir definições fechadas sobre as correntes políticas. Todo pensamento, toda teoria, toda corrente de pensamento é historicamente modelada e historicamente ressignificada. Assim, o conservadorismo do século XIX não é o mesmo da segunda metade do século XX, bem como não é o mesmo no Brasil, nos EUA e na Inglaterra (mantendo os mesmos recortes temporais comparativos). Isso complica muito a vida do pesquisador, mas ainda mais a da população que pode orientar suas escolhas, por exemplo, pelo "liberalismo" de hoje, pensando que ele representa o liberalismo do século XIX.

Por outro lado se mantemos o termo conservadorismo, liberalismo, fascismo, comunismo, etc. no meio destas constantes mutações de significado e de objetivos (constituídos por cada momento específico de luta política) algo tem que permanecer constante, caso contrário a fronteira entre uma corrente e a outra não poderia ser estabelecida (e não estou aqui me referindo as barbaridades que vemos no debate público atual, no qual qualquer forma de oposição é tacha da de comunismo ou qualquer forma de redução da dimensão pública protetiva é definida como fascismo). No caso do binômio direita-esquerda eu entendo que olimite que permanece constante é marcado pelo papel atribuído à política - como meio limitado à regulação do conflito (direita) versus instrumento de superação das matrizes do conflito (esquerda). Nesta dimensão a variável positivada pela direita seria um racionalismo calcado no ceticismo (desconfiança da potência humana, das grandes teses e naturalizador da ordem natural do mundo como reino da desigualdade), enquanto a variável positivada pela esquerda 
seria o racionalismo e a vontade política da transformação (concepção da desigualdade como socialmente produzida e, por extensão, socialmente superável). O resultado é apoiar, ou reforçar, a desigualdade ou lutar pela sua erradicação.

Os argumentos são muitos de cada lado, mas o horizonte de fundo permanece o mesmo para cada campo, mudando, insisto, sob cada condição histórico-conjuntural específica e que, por sua vez, tem o efeito de reposicionar parcelas desse discurso, significado e de mudança de alianças. O que me assusta na direita atual é uma convergência entre um conservadorismo e uma direita tradicional, que desconfiavam do individualis mo e das forças seculares do mercado aos propósitos do ultraliberalismo e do anarco-capitalismo. No fundo, a coerência é que todas estas correntes entendem bem de desigualdade (sob o império de Deus ou do Capital), mas o curioso é a associação entre esses "dois deuses" em uma mesma chave política.

Ainda no tema das novas direitas, muitos estudos atuais vêm mobilizando conceitos como populismo, bonapartismo e fascismo. Como entende este debate suscitado pela crise das democracias liberais e ascensão de novas expressões do autoritarismo no mundo e também no Brasil?

Aqui eu apontaria de saída três problemas sérios. O primeiro é o da redução da democracia à sua fórmula eleitoral, quando na verdade houve uma convergência histórica associando um Estado sub leges e per leges (baseado tanto da proteção dos direitos civis e políticos como na organização da luta política dentro das "regras do jogo"), uma exigência fundamental para ação do Estado - a garantia da paz e o impedimento da produção ou agravamento do conflito pelo próprio ente estatal -, a condição da ação estatal nos moldes da concepção de res publica (não patrimonial) e a garantia do poder dos cidadãos de controle do Estado via processos eleitorais (que na melhor das hipóteses poderiam caminhar rumo à poliarquia de Dahl ou a combinação de dispositivos da participação via instâncias de democracia direta). Eu entendo que os processos eleitorais, face à qual em geral as instituições democráticas são reduzidas, está permitindo a ascensão de grupos não democráticos ao poder pela via eleitoral, e que uma vez entronizados nesses cargos poderão modificar a democracia por dentro, 
inclinando a sociedade para uma versão autoritária de menoridade política e supressão de direitos.

Nesse contexto, surge uma nova forma de autoritarismo, apoiado em retalhos das instituições democráticas (eleições, nas quais precisaríamos inclusive observar se são reais, competitivas, plurais) e de populismo (plebiscitário? De massas?). Este seria o segundo problema apontado - as estruturas funcionais de um atual "populismo, fascismo ou bonapartismo" assumem objetivos e configurações muito inusitadas - em especial depois da onda democrática generalizada (nem sempre tal real quanto formal) posterior ao final da segunda guerra mundial.

O terceiro problema grave é recuperar a compreensão do grau de fissura social e de produção de conflito gerado pelo capitalismo desregulado (há algumas décadas o chamávamos de selvagem), bem como sua relação contraditória com a democracia, em especial na sua capacidade de redistribuição. É difícil recusar a evidência de que uma das funções da democracia (não apenas das eleições) é produzir efeitos de minoração do conflito social -será então que os interesses capitalistas coincidem com os interesses de uma sociedade democrática?

Observe, estou nesta resposta pensando em voz alta, porque esta reflexão me preocupa e tenho girado nos últimos anos em torno dela - as contradições entre democracia e modernização econômica no Brasil são bons exemplos desse dilema, que não sendo novo está, no entanto, assumindo nova configuração (e não só no Brasil).

Por fim: o que você vislumbra de futuro para a política e para a sociedade brasileira? "O que será o amanhã”, considerando as configurações do passado e do presente, com a extrema direita no poder aprofundando as pautas neoliberais com toda força, as esquerdas sem direção e sem um projeto capaz de unir as forças populares em meio ao crescimento do desemprego, da precarização, da miséria e da desesperança?

No caso do Brasil, na caixinha de Pandora ficaram algumas esperanças que acho precisamos libertar. Uma delas é a enorme energia política que a história política brasileira demonstrou ao conceber a ação estatal como fundamental para a mudança social. Nem todos os países passaram por uma experiência de reconhecer as 
capacidades do Estado como elemento central da vida pública. Não é a toa que esse tema está no centro da disputa política desde a década de 1930 - e não estou me referindo à Era Vargas, mas da disputa por separar desenvolvimento de crescimento econômico e que sempre opôs os mensageiros do mercado (Gudin, Bulhões, Delfim, Campos, nos anos 40/70; P. Arida, A. L. Resende, G. Franco, no período neoliberal) dos mensageiros da sociedade nacional (Simonsen, Furtado, I. Rangel, Rômulo de Almeida nos anos 40/70; L. G. Belluzzo, L. Coutinho, Ricardo Carneiro, Márcio Pochmann, Bresser-Pereira, Ricardo Bielschowsky, no período novo-desenvolvimentista).

A segunda, que pode parecer inicialmente contraditória, é reconhecer que a energia do nacional-desenvolvimentismo sob o modelo autoritário pós-64 foi responsável pela produção de uma nova onda de pobreza e de formas violentas de desigualdade, talvez superiores aquelas que herdamos da herança colonial mercantilexportadora. Mas, se uma vez usamos os recursos públicos e a energia nacional em direção pervertida, é possível retomá-la em outra direção porque temos essa técnica. Essa pode ser uma boa explicação para a cólera da direita brasileira para desqualificar o papel do Estado - estamos novamente às voltas com os mensageiros do mercado, que dizem com clareza que é preciso "destruir tudo que está aí".

Portanto, o desafio é exatamente no campo da luta cultural, como a direita não cansa de dizer, porque temos que recuperar uma visão de política - e não de Mercado - que está na nossa tradição, mas sob fortíssima e furioso ataque. 